\title{
Molecular Study of Acalypha indica to Leptin, Alpha Glucosidase, and its Antihyperglycemic Effect on Alpha Glucosidase
}

\author{
Rani Wardani Hakim ${ }^{1,2,6, *}$, Fadilah Fadilah ${ }^{3,6,7}$, Tri Juli Edi Tarigan ${ }^{4}$, Sri Widia A Jusman ${ }^{5}$, Erni H Purwaningsih ${ }^{2,6}$
}

\section{Rani Wardani Hakim ${ }^{1,2,6, *}$, Fadilah Fadilah $^{3,6,7}$, Tri Juli Edi Tarigan ${ }^{4}$, Sri Widia A Jusman ${ }^{5}$, Erni $\mathrm{H}$ Purwaningsih ${ }^{2,6}$}

${ }^{1}$ Doctoral Program in Biomedical Sciences, Faculty of Medicine, Universitas Indonesia, Jakarta 10430, INDONESIA.

${ }^{2}$ Department of Medical Pharmacy, Faculty of Medicine, Universitas Indonesia, Jakarta 10430, INDONESIA.

${ }^{3}$ Department of Medical Chemistry, Faculty of Medicine, Universitas Indonesia, Jakarta 10430, INDONESIA.

${ }^{4}$ Division of Endocrinology, Department of Internal Medicine, Dr. Cipto Mangunkusumo National Referral Hospital, Faculty of Medicine, Universitas Indonesia, Jakarta 10430, INDONESIA

${ }^{5}$ Department of Biochemistry and Molecular Biology, Faculty of Medicine, Universitas Indonesia, Jakarta 10430, INDONESIA.

${ }^{6}$ Drug Development and Research Cluster, The Indonesian Medical Education and Research Institute, Faculty of Medicine, University of Indonesia, Jakarta 10430 INDONESIA.

${ }^{7}$ Bioinformatics Core Facilities, The Indonesian Medical Education and Research Institute, Faculty of Medicine, University of Indonesia, Jakarta 10430, INDONESIA.

\section{Correspondence}

\section{Rani Wardani Hakim}

Doctoral Program in Biomedical Sciences; Department of Medical Pharmacy; Drug Development and Research Cluster,

The Indonesian Medical Education and Research Institute, Faculty of Medicine, University of Indonesia, Jakarta 10430, INDONESIA

E-mail: rani.wardani1708@ui.ac.id

History

- Submission Date: 04-08-2021;

- Review completed: 25-08-2021.

- Accepted Date: 02-09-2021.

DOI : 10.5530/pj.2021.13.211

Article Available online http://www.phcogj.com/v13/i6

\section{Copyright}

(C) 2021 Phcogj.Com. This is an openaccess article distributed under the terms of the Creative Commons Attribution 4.0 International license.

\section{ABSTRACT}

Introduction: The purpose of this study is to find potential inhibitors of leptin as a proinflammatory adipokine and alpha glucosidase as an enzyme that mediate hyperglycaemia; to alter the chronic complications of obesity from herbal Acalypha indica (Ai). This study was conducted using in silico molecular docking to evaluate the Ai compounds interaction with leptin and alpha glucosidase. The in vitro assay to alpha glucosidase was done to explore antihyperglycemic effect of $\mathrm{Ai}$, as hyperglycaemia is the key process of chronic complication of obesity. Material and Methods: Protein target were leptin and alpha glucosidase; compounds from Ai plant were repundusinic, mauritanin, hesperetin, acaindinin, and glucogalin in pdb format. Molecular docking using autodock vinna. In vitro assay of Ai antihyperglycemic activity was done to alpha glucosidase and was define as IC50 level. Result: The results from the docking analysis demonstrated that compounds from Ai roots contain antihyperglycemic-antiobesity activity which acted by inhibiting leptin and alpha glucosidase receptors. Repundusininc and mauritanin compounds contain hydrogen bond with the greatest leptin enhancer activity on Ser9, Thr35, Glu8, Ser9, Thr25, Gln111, Lys211, Leu7 for repundisinic and Glu8, Thr25, Gly112 and Leu7 for mauritanin. Hesperetin, acaindinin and glucogallin were the most identical compounds with similar affinity binding value to alpha glucosidase. Ai roots was already proven as anti-hyperglycemic-antiobesity which was further confirmed by in vitro assay to alpha glucosidase (IC50 19,429 $\mathrm{mg} / \mathrm{ml}$.). Conclusion: The results demonstrated that $A i$ have anti hyperglycaemic-antiobesity effects and was found to be potentially as antihyperglycemic by in vitro assay to alpha glucosidase.

Key words: Acalypha indica, Antiobesity, Leptin, Alpha glucosidase.

\section{INTRODUCTION}

Obesity is defined as abnormal or excessive fat accumulation that presents a risk to health. ${ }^{1,2}$ Nowadays, obesity has become a global health problem..$^{3-5}$ Availability of highly processed foods, which are very easy to handle or do not require any handling and-most importantly-are very cheap, contributes greatly to the continuous increase in the incidence of obesity. ${ }^{1}$ Obesity is associated with impaired glucose tolerance or type 2 diabetes mellitus. The underlying mechanism is due to insulin resistance which results in further complications of obesity. ${ }^{6}$

Leptin is the product of the obesity $(\mathrm{Ob})$ gene and currently considered as a satiety hormone. ${ }^{7}$ Leptin is released into the circulating blood; transported to the brain and bound to its receptors in the hypothalamus, where it causes repression of genes encoding neuropeptide Y (NPY) and induction of genes encoding proopiomelanocortin (POMC) and corticoliberin (CRH). ${ }^{7,8}$ This results in decreased appetite and reduced food intake with subsequent body fat reduction and increased energy expenditure, which finally leads to body mass decrease. ${ }^{7}$ Leptin has been shown to enhance insulin sensitivity in peripheral tissues and increase glucose uptake and oxidation in skeletal muscles. ${ }^{9}$ In leptin resistant over-weight individuals, the permeability of the blood brain barrier (BBB) to leptin is decreased in high-fat diet-induced obesity despite the increase in plasma leptin levels. This impaired transport of leptin across the BBB is one of the causes of leptin resistance. Insufficiency of leptin signaling in the hypothalamus (induced by hyperleptinemia in obese subjects), causes hyperglycemia and hyperinsulinemia, which lead to diabetes mellitus. ${ }^{10}$

Alpha-glucosidases are enzymes in the digestive tract that hydrolyze carbohydrates into glucose. ${ }^{11}$ In particular, mammalian $\alpha$-glucosidase in the mucosal brush border of the small intestine catalyzes the end step digestion of starch and disaccharides that are abundant in the human diet causing an increase of blood glucose. Inhibitors of alpha-glucosidases delay the breakdown of carbohydrates in the small intestine and diminish the postprandial blood glucose excursion. Thus, inhibition of glycosidases has a significant effect on polysaccharide metabolism, glycoprotein processing, and cellular interaction. This mechanism widens opportunities for the discovery and development of new therapeutic agents against diabetes and obesity.

Considering the complexity of chronic complications that could be happen in obesity patient, it seems probable that it will be necessary to apply combined treatment, with pathways directed at various types of cells in various stages of the disease process. Acalypha indica $L(\mathrm{Ai})$ has a promising potential to be developed as an herb to treat obesity. Ai comes from the Euphorbiaceae family and taxonomically belongs to the genus Acalypha which is the fourth largest genus in the Euphorbiaceae family. ${ }^{12}$ This plant can grow to $1.5-2.5 \mathrm{~m}$ and has empirically been used to treat diabetes and hyperlipidaemia. Most of the international manuscripts on Ai were published from the Indian region because this plant

Cite this article: Hakim RW, Fadilah F, Tarigan THE, Jusman SWA, Purwaningsih EH. Molecular

Study of Acalypha indica to Leptin, Alpha Glucosidase, and its Antihyperglycemic Effect on Alpha Glucosidase. Pharmacogn J. 2021;13(6)Suppl: 1639-1647. 
has a close relationship with Ayurvedic medicinal practices done by the older Indian generation. Meanwhile, in other countries, this plant is used for medical purposes but is still limited. ${ }^{12}$ Various studies have been conducted to determine the effect of $\mathrm{Ai}$ administration on diseases associated with metabolic syndrome. However, the effect of Ai on inflammatory adipokines such as leptin and alpha glucosidase as enzymes of obesity-related metabolic syndrome has not been studied.

The purpose of this study is to explore the molecular docking of Acalypha indica active compounds to leptin and alpha glucosidase which has a role to overcome chronic complications of obesity such as hyperlipidemia, cardiovascular abnormalities, and atherosclerosis. The molecular docking study is assessed by binding energy values. Binding energy values are the sum of intermolecular energies $(\mathrm{kcal} / \mathrm{mol})$, comprising hydrogen bond energy, Van Der Waals energy, desolvation energy, and electrostatic energy. Binding energy is described as the energy released due to the interaction between a ligand and its receptor. The ligand with the less binding energy had a greater possibility of interacting with a protein target. The level of the compound affinity to the molecular target is represented by the $\mathrm{pKi}$ value. The ligand with greater $\mathrm{pKi}$ value has more possibility to interact with a protein target.

Furthermore, in vitro assay of Acalypha indica roots extract to alpha glucosidase were done in this study to assess its antihyperglycemic effect, reminding hyperglycemia is the main condition in obesity related to metabolic syndrome which often causes chronic complications such as heart diseases and stroke.

\section{MATERIAL AND METHOD}

\section{Computational Materials}

All computational studies to perform molecular docking were done using MacBook Air with High Sierra 10.13.3, 1.8GHz Intel Core i5 processor, 8 GB RAM, $1600 \mathrm{MHz}$ DDR3. Marvin Sketch was used to draw ligand structures in 2 and 3 dimensions. AutoDockVina was used for docking process, while AutoDockTools was used to analyze the docking result and create $3 \mathrm{D}$ visualization of the ligand-receptor complex. LigPlus was used for the analysis of the amino acid residues of 2D ligand-receptor complex.

\section{Receptor Preparation}

We downloaded the receptor from www.rcsb.org in the .pdb file format and performed separation between the receptor chain and ligands. The water was removed by deleting water in Autodock software and hydrogen atoms (polar only) was added and non polar atoms were merged. Finally, gesteiger load was added to the recipe and the file was saved as .pdbqt.

\section{Preparation of ligands}

The native PDB ligand was isolated from the receptor ligand complex (specifically the ligand from the PDB receptor ligand complex). Images of 50 compounds were download from Chemspide in .pdb file format using Marvin Sketch.

\section{Validate the docking method}

We performed docking on the original PDB ligands by optimizing the grid box size and grid center position. The optimum grid box and grid center were selected by looking at the docking results.

\section{Docking and analysis of docking results}

A folder containing proteins and ligands was created in the .pdbqt format and the docking configuration (protein file name, ligand file name, grid box coordinates, grid box size, output file name, and the number of models produced) was set. AutodockVina was used to run the docking through the terminal. The docking file output (.pdbqt) was separated by the best docking model with vina split and docking receptor-ligand complexes were analyzed and visualized through Ligplus.

\section{Extraction and Phytochemical Test}

Acalypha indica $L$ dry-powder underwent maceration process with $96 \%$ ethanol, ethyl acetate, and n-hexane for 3x24 hours. Extract and solvent was separated with a rotary evaporator and stored in oven until it become solvent free. The phytochemical analysis of saponin, flavonoid, tannin, glycoside, triterpenoid, steroid, and alkaloid were carried out using chemical reactions.

\section{In vitro Assay to Alpha- Glucosidase}

Alpha-glucosidase assay of extracts was carried out according to literature with slight modification. ${ }^{13}$ In a 96 -well plate, reaction mixture containing $120 \mu \mathrm{l}$ phosphate buffer $(0,1 \mathrm{M}, \mathrm{pH}=6.9)$, $20 \mu \mathrm{l}$ alphaglucosidase $(0,5 \mathrm{U} / \mathrm{ml}), \quad 20 \mu \mathrm{l} \quad \mathrm{p}$-nitrophenyl- $\alpha$-D-Glucopyranoside (PNPG) $(5 \mathrm{mM})$, and $10 \mu \mathrm{l}$ of varying concentrations of extracts was preincubated at $37^{\circ} \mathrm{C}$ for $15 \mathrm{~min}$. The reaction was stopped by adding $80 \mu \mathrm{l}$ sodium carbonate $(0.2 \mathrm{M})$. The yellow color produced was read at $405 \mathrm{~nm}$ using microplate Reader. Each experiment was performed in triplicates, along with appropriate blanks. Acarbose at various concentrations (0.1-10 $\mu \mathrm{g} / \mathrm{ml})$ was included as a standard. Negative control without extracts was set up in parallel. The results were expressed as percentage inhibition, which were calculated as:

Inhibition (\%) $=A_{\text {Negative control }}-A_{\text {Test }} / A_{\text {Negative control }} X 100$,

where, $A$ is absorbance. The result is also expressed as $\mathrm{IC}_{50}$ value.

\section{RESULT}

The Ai compounds were assessed through the energy variation and the formation of the ligand-receptor structure, given by the binding constant and the Gibbs free energy $(\Delta G)$ values. Ligand-protein binding was evaluated by their binding affinity, binding structure, binding energy, and residue component.

Based on the result of docking with leptin (Table 1), repandusinic bound to leptin with the least binding energy $-7,3495 \mathrm{kcal} / \mathrm{mol}$ and pKi 10,237. Repandusinic bound to leptin with 8 hydrogen bindings which involved binding sites of Ser9, Thr35, Glu8, Ser9, Thr25, Gln111, and Leu7 (Table 1). Another significant compound binding to Leptin is mauritanin with a binding energy of $-5,6617 \mathrm{kcal} / \mathrm{mol}$ and $\mathrm{pKi} 7,886$. Mauritanin had hydrogen bound to leptin in sites Glu8, Thr25, Gly112 and Leu7. In visual observation through the docking simulation (Figures 1 and 2), the two observed ligands (repandusinic and mauritanin) made similar conformation to Leptin structure on the active site.

On the other hand, the study of alpha glucosidase molecular docking to $\mathrm{Ai}$ (Table 2) determined that hesperetin has the least binding energy of $-7,2135 \mathrm{kcal} / \mathrm{mol}$ and $\mathrm{pKi} 11,2135$. Hesperetin bound to alpha glucosidase with 7 hydrogen bindings which involved binding sites of His34, Asp303, Asp633, Phe30, His34, His691, and Glu29 (Table 2 ). Another significant compound binding to alpha glucosidase is acaindinin with a binding energy of $-6,7586 \mathrm{kcal} / \mathrm{mol}$ and $\mathrm{pKi} 10,667$. Acaindinin had 10 hydrogen binding sites which involved binding sites of Tyr746, Tyr 747, Asn765, His825, Glu858, Lys742, His825, Arg880, and Lys387. Glucogalin bound to alpha glucosidase with a binding energy of $-5,1502 \mathrm{kcal} / \mathrm{mol}$ and pKi 9,823. Gly764, His825, Tyr893, Lys742, Asn765, His825, Arg880, Tyr893, and Thr738 were hydrogen binding sites of glucogalin to alpha glucosidase. In visual observation through the docking simulation (Figure 3, 4 and 5), the three observed ligands (hesperetin, acaindin, and glucogalin) made similar conformations to alpha glucosidase molecule on the active site. 
Table 1: Binding energy and residue components of each ligand with leptin.

\begin{tabular}{lllll}
\hline No & Molecules & $\Delta \mathrm{G}(\mathrm{kcal} / \mathrm{mol})$ & $\mathrm{KI}$ & H don and H acc \\
\hline 1 & Repandusinic acid B & -7.3495 & 10,237 & Ser9, Thr35, Glu8, Ser9, Thr25, Gln111, Lys211, and Leu7 \\
2 & Tannin & -6.9753 & 8,927 & Thr25, Asp633, Phe30, His34 \\
3 & Chebulagic & -5.7741 & 7,925 & Phe30, Gly112 \\
4 & Mauritanin & -5.6617 & 7,886 & Glu8, Thr25, Gly112 and Leu7 \\
5 & Clitorin & -5.4841 & 7,561 & Glu8, Ser9 \\
6 & Acalyphamide & -5.1322 & 6.925 & Asp633, \\
7 & Tri-O-Metylellagic & -5.0676 & 6.820 & Pro206 \\
8 & Acetonylgreanin & -5.0603 & 6.729 & Thr35 \\
9 & Geranin & -4.9229 & 5.736 & Gly112 \\
10 & Acalyphin amide & -4.7762 & 5.509 &
\end{tabular}

$\Delta \mathrm{G}$ (mean binding energy); pKi (binding affinity), $\mathrm{H}$ don (Hydrogen donor); $\mathrm{H}$ acc (Hydrogen Acceptor)

Table 2: Binding energy and residue components of each ligand with alpha glucosidase.

\begin{tabular}{lllll}
\hline No & Molecules & $\Delta \mathrm{G}(\mathrm{kcal} / \mathrm{mol})$ & pKI & H don and H acc \\
\hline 1 & Hesperetin & -7.2135 & 11,673 & His34, Asp303, Asp633, Phe30, His34, His691, and Glu29 \\
2 & Chrsysin & $-7,0256$ & 10,902 & His691, and Glu29, Phe30 \\
3 & Acaindinin & $-6,7586$ & 10,331 & Asn765, His825, Lys742, His825, Arg880 \\
4 & Tannin & $-6,3464$ & 10,667 & Tyr746, Tyr 747, Asn765, His825, Glu858, Lys742, His825, Arg880, and Lys387 \\
5 & Chebulagic acid & $-5,9039$ & 10,030 & Arg880, Tyr893, Thr738 \\
6 & Geranin & $-5,8510$ & 9,922 & Gly764, His825, Tyr893, Lys742, Asn765 \\
7 & Glucogallin & -5.1502 & 9,823 & Gly764, His825, Tyr893, Lys742, Asn765, His825, Arg880, Tyr893, Thr738 \\
8 & Acetonylgreanii & $-4,9814$ & 8,739 & His825 \\
9 & Mauritanin & -4.9628 & 8,654 & Tyr893 \\
10 & Kaempferol & $-4,9597$ & 7,938 & Arg880
\end{tabular}

$\Delta \mathrm{G}$ (mean binding energy); pKi (binding affinity), $\mathrm{H}$ don (Hydrogen donor); $\mathrm{H}$ acc (Hydrogen Acceptor)

Table 3: Inhibition percentage and IC50 value of acalypha and acarbose towards a-glucosidase.

\begin{tabular}{|c|c|c|c|c|c|c|c|c|c|}
\hline \multirow{2}{*}{ Sample } & \multirow{2}{*}{$\begin{array}{c}\text { Cons (mg/ } \\
\mathrm{ml})\end{array}$} & \multicolumn{3}{|c|}{ \%Inhibition } & \multirow[t]{2}{*}{ Mean Inh } & \multicolumn{2}{|c|}{ IC50 (mg/ml) } & \multicolumn{2}{|c|}{ Mean IC50 (mg/ml) } \\
\hline & & 1 & 2 & 3 & & 1 & 2 & 3 & \\
\hline \multirow{8}{*}{$\begin{array}{l}\text { Ai roots } \\
\text { ethanol } \\
\text { extract }\end{array}$} & 12,5 & 47,684 & 49,380 & 48,076 & $48,380 \pm 0,888$ & \multirow{8}{*}{19,683} & \multirow{8}{*}{18,947} & \multirow{8}{*}{19,655} & \multirow{8}{*}{19,429} \\
\hline & 25 & 50,554 & 50,424 & 51,468 & $50,815 \pm 0,569$ & & & & \\
\hline & 50 & 59,556 & 58,121 & 57,860 & $58,513 \pm 0,913$ & & & & \\
\hline & 100 & 62,557 & 62,296 & 62,035 & $62,296 \pm 0,261$ & & & & \\
\hline & 200 & 65,427 & 64,644 & 64,123 & $64,731 \pm 0,656$ & & & & \\
\hline & 400 & 66,601 & 69,602 & 69,472 & $68,558 \pm 1,696$ & & & & \\
\hline & 800 & 82,909 & 81,213 & 79,909 & $81,344 \pm 1,504$ & & & & \\
\hline & 1600 & 84,083 & 84,083 & 84,214 & $84,127 \mathrm{C} 0,076$ & & & & \\
\hline \multirow{7}{*}{$\begin{array}{l}\text { Acarbose } \\
\text { (standard) }\end{array}$} & 0,156 & $-1500,274$ & $-1666,301$ & $-1786,301$ & $-1650,958 \pm 143,629$ & \multirow{7}{*}{1,461} & \multirow{7}{*}{1,502} & \multirow{7}{*}{1,581} & \multirow{7}{*}{1,515} \\
\hline & 0,3125 & $-1211,781$ & $-1271,781$ & $-1298,082$ & $-1260,547 \pm 44,233$ & & & & \\
\hline & 0,625 & $-929,863$ & $-993,973$ & $-1127,123$ & $-1016,986 \pm 100,623$ & & & & \\
\hline & 1,25 & $-651,233$ & $-567,397$ & $-671,781$ & $-630,137 \pm 55,297$ & & & & \\
\hline & 2,5 & $-522,192$ & $-436,712$ & $-519,726$ & $-492,877 \pm 48,655$ & & & & \\
\hline & 5 & $-411,233$ & $-384,110$ & $-359,452$ & $-384,931 \pm 25,9$ & & & & \\
\hline & 10 & $-357,808$ & $-274,795$ & $-356,164$ & $-329,589 \pm 47,460$ & & & & \\
\hline
\end{tabular}

This result was supported by the in vitro assay of Ai extract to alpha glucosidase. The $\mathrm{IC}_{50}$ of $\mathrm{Ai}$ extract to alpha glucosidase was 19,429 $\mathrm{mg} / \mathrm{ml}$ compared to $\mathrm{IC}_{50}$ of Acarbose, an established alpha glucosidase inhibitor, was $1,515 \mathrm{mg} / \mathrm{ml}$ (Table 3 ). This activity is probably due to the content of polyphenol compounds in Ai, like flavonoid compounds. The results of the phytochemical screening of Ai are as shown in Table 4; flavonoid, tannin and triterpenoid were positive in $\mathrm{Ai}$ roots of ethanol extract.

\section{DISCUSSION}

\section{Molecular Study of Ai to Leptin}

Leptin, the adipocyte hormone, is well known for its role in the regulation of food intake and energy expenditure. Since the discovery of leptin, leptin is acknowledged for its therapeutic potential to obesity and diabetes. 

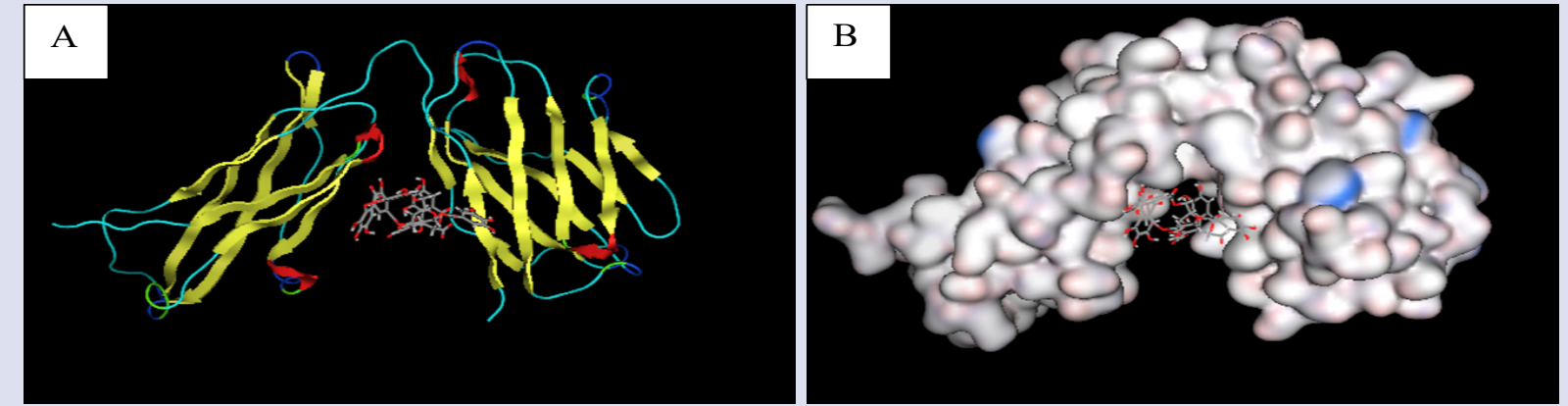

Figure 1. A. Repandusinic. B. Model binding of repandusinic acid and leptin.
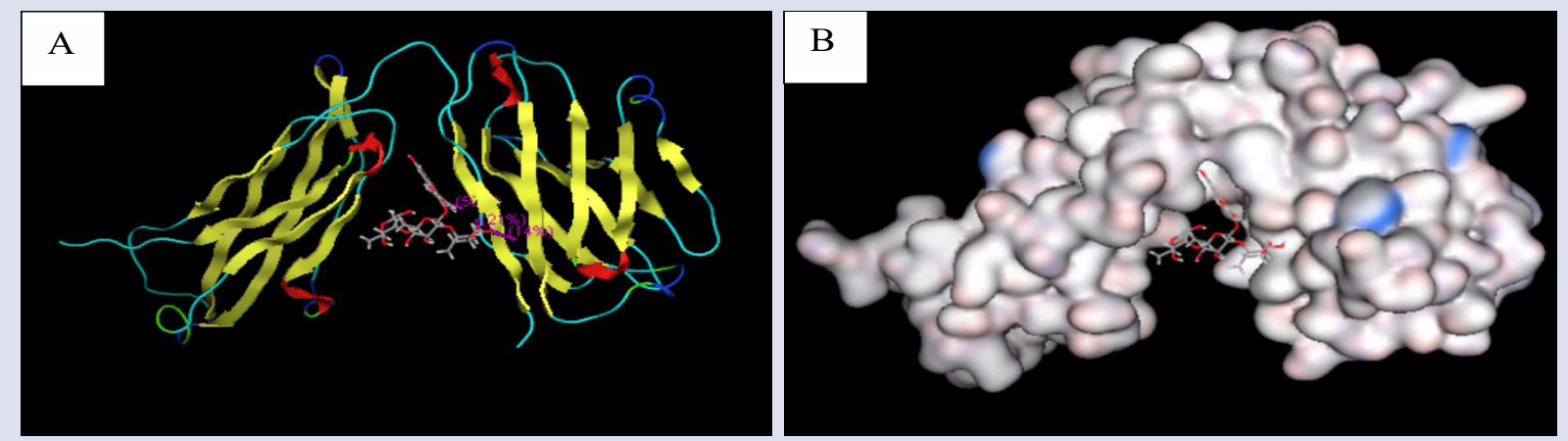

Figure 2. A. Mauritanin. B. Model binding of mauritanin and leptin

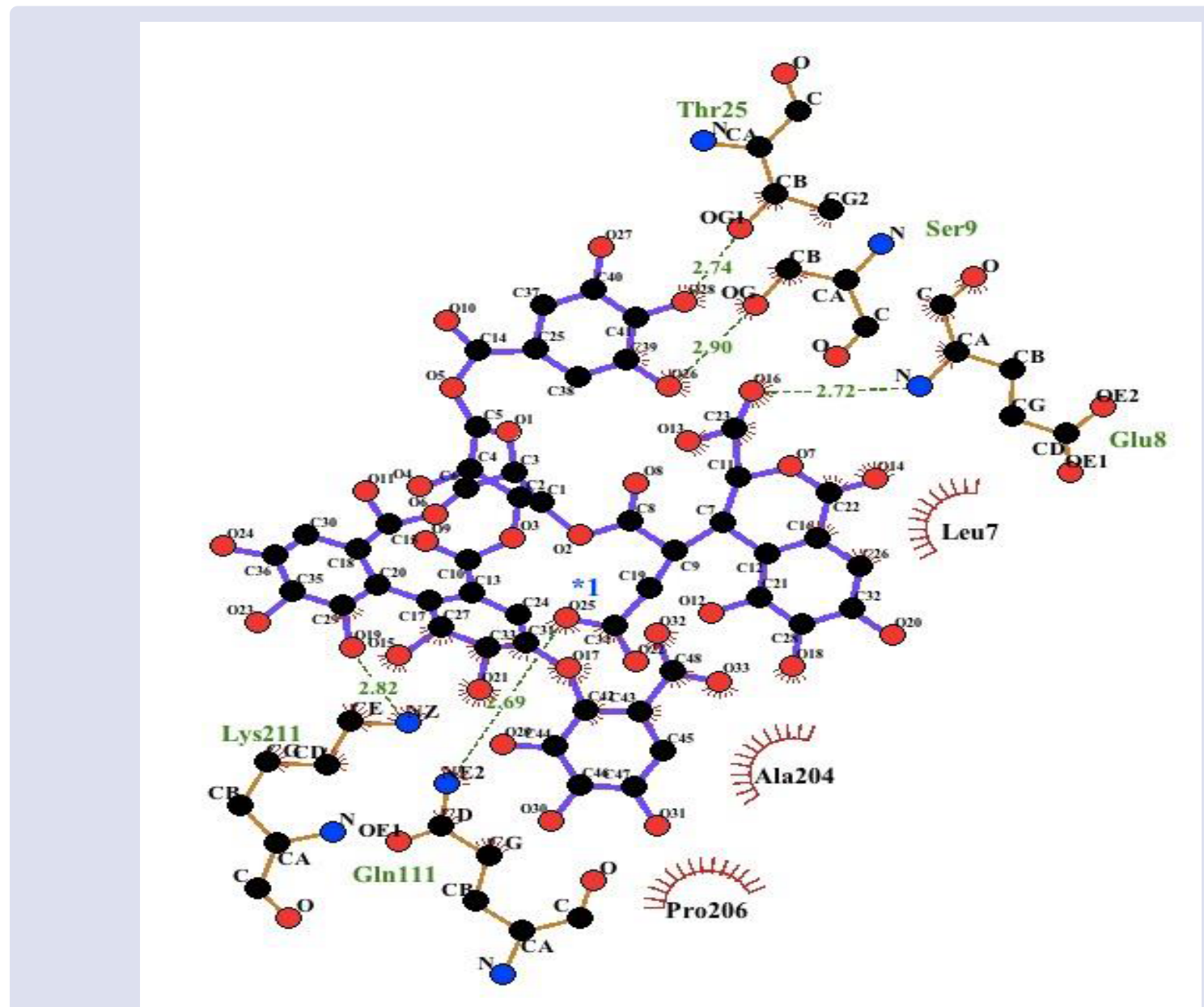

Figure 3.2D Interaction between repandusinic and leptin. 

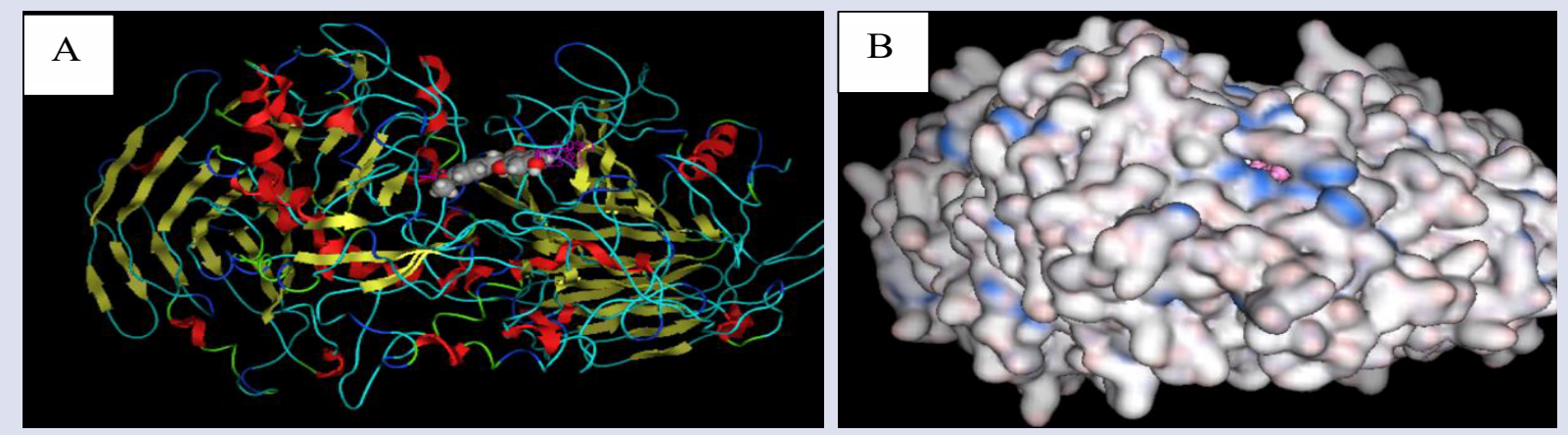

Figure 4. A. Hesperetin. B. Model binding of hesperetin and alpha glucosidase.
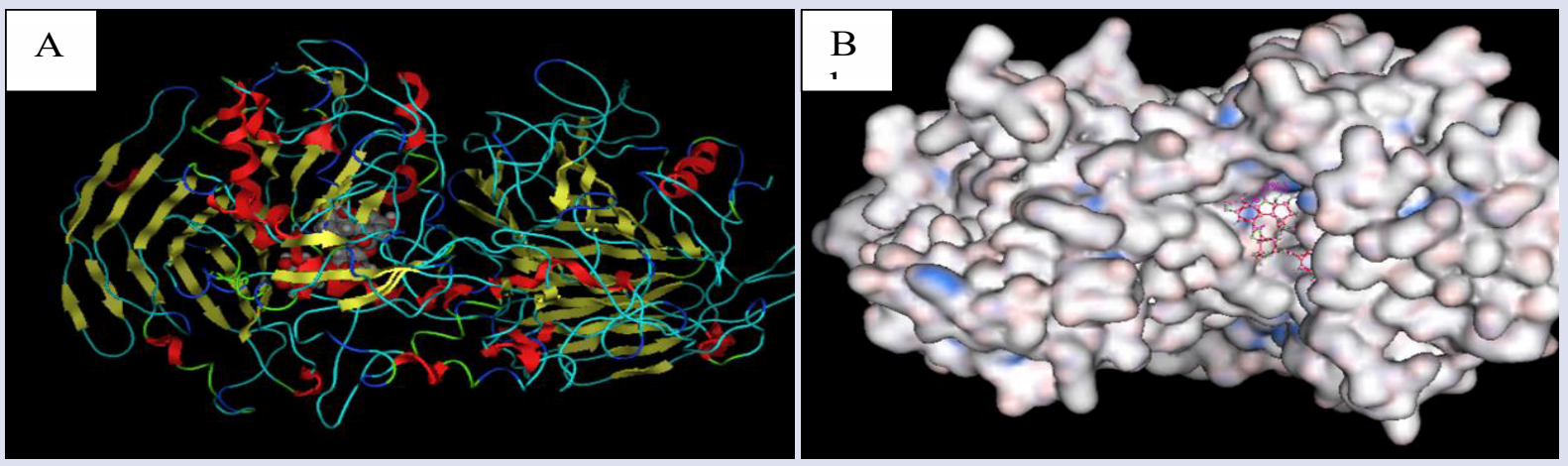

Figure 5. A. Acaindinin. B. Model binding of acaindinin and alpha glucosidase.
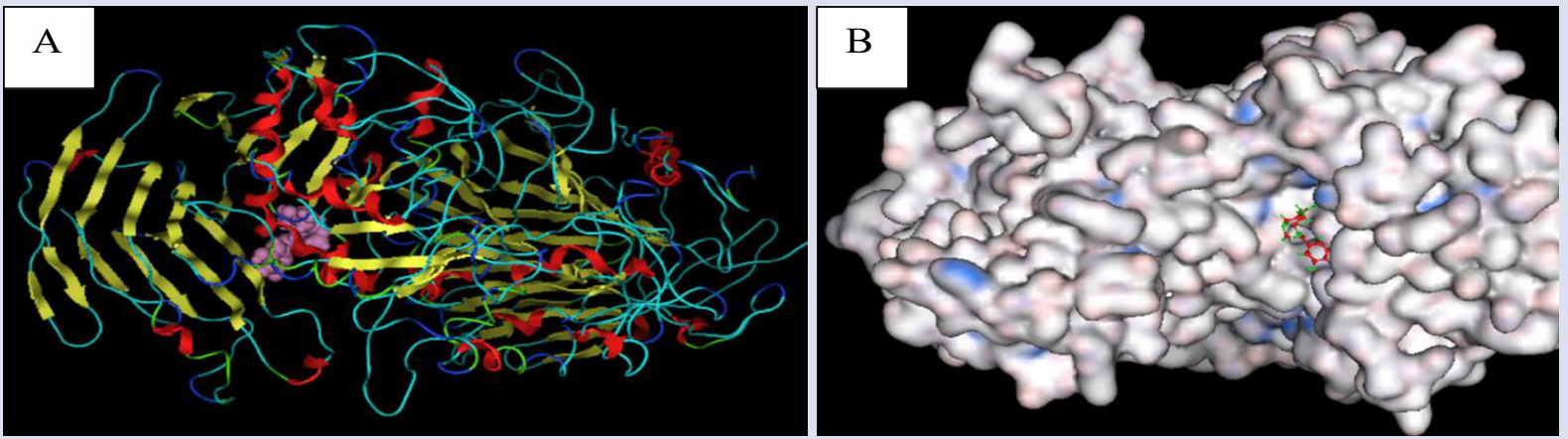

Figure 6. A. Glucogalin. B. Model binding of glucogallin and alpha glucosidase.

Table 4: Phytochemical screening result of Acalypha indica extract.

\begin{tabular}{|lcccc} 
& Metabolite & Ethanol Extract & Ethyl Acetate Extract & $n$-Hexane Extract \\
\hline $\mathbf{1}$ & Saponin & - & - & - \\
$\mathbf{2}$ & Flavonoid & + & + & - \\
$\mathbf{3}$ & Tannin & + & + & - \\
$\mathbf{4}$ & Glycoside & - & - & + \\
$\mathbf{5}$ & Triterpenoid & + & + & - \\
$\mathbf{6}$ & Steroid & - & + & + \\
$\mathbf{7}$ & Alkaloid & - & + & + \\
\hline
\end{tabular}




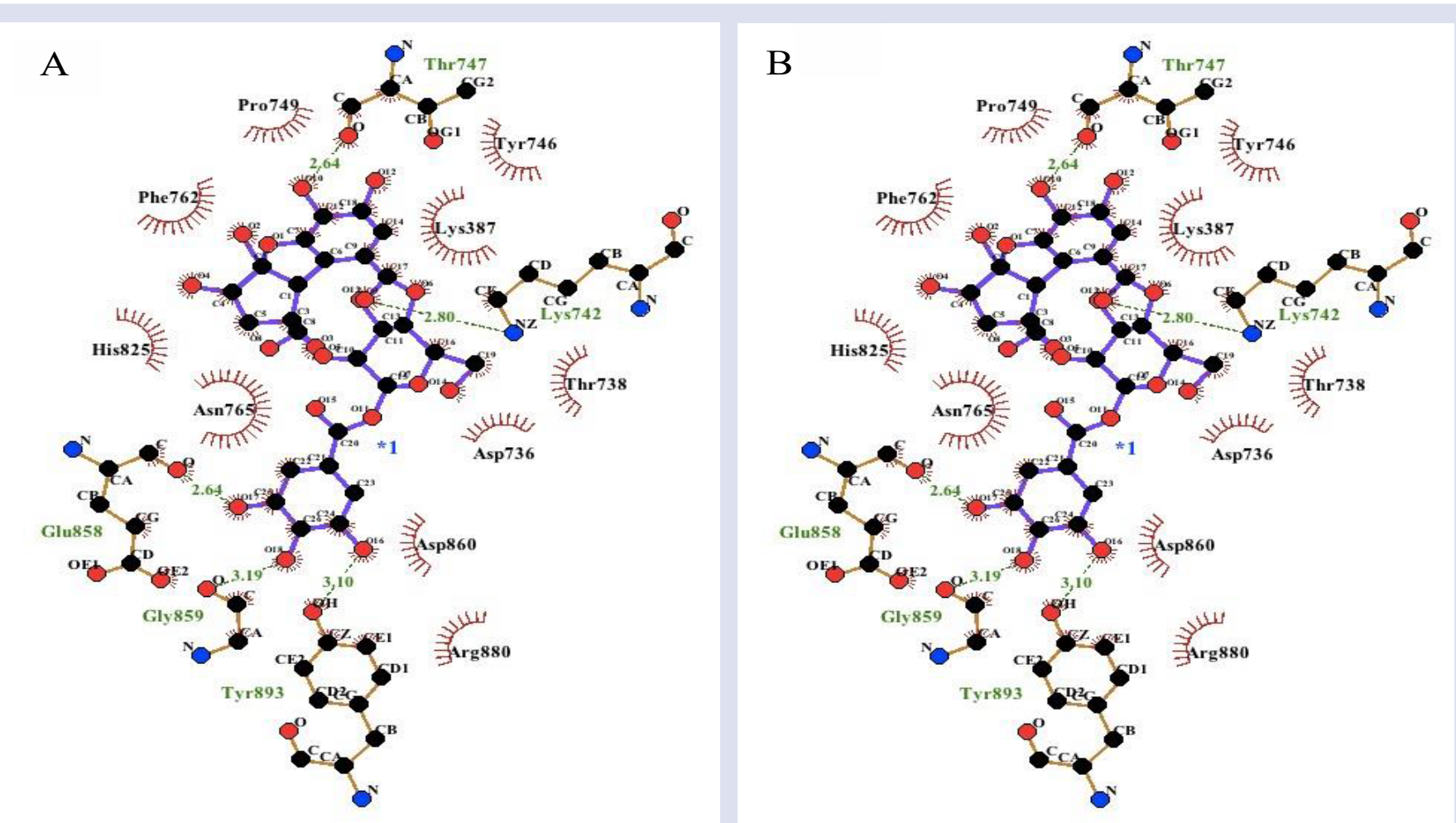

Figure 7.2D Interaction between: A. acaindinin and B. glucogallin with alpha glucosidase.

From the Ai molecular docking study, we understood that repandusinic acid and mauritanin are Ai compounds that have strong interactions with leptin. The strong binding between ligan and protein in molecular docking is described by lowest $\Delta \mathrm{G}$, highest pKI and many hydrogen bonds between them. Repandusinic acid has the lower $\Delta \mathrm{G}(-7.3495 \mathrm{kcal} /$ $\mathrm{ml})$, the stronger $\mathrm{pKI}(10,237)$ and more hydrogen bonds $(7$ hydrogen bonds) compare to mauritanin $(\Delta \mathrm{G}-5,6617 \mathrm{kcal} / \mathrm{ml}$, pKI 7,886, and 5 hydrogens bonds). Either repandusinic acid and mauritanin has a perfect conformation site to inhibit leptin receptors. Repandusinic acid is the main alkaloid of Phyllanthus amarus medicinal plant. It was confirmed to have a wide range of biopotential for many disease complications, which includes radical scavenging activity. ${ }^{14}$

Phil Scherer et al. reported that in mice with diet-induced obesity, a partial reduction of circulating leptin either by genetic approaches or by a leptin neutralizing antibody restores sensitivity of the body to the remaining circulating leptin, resulting in weight loss and improvements in diabetes. Thus, he proposed a major conceptual shift to the treatment of obesity; namely, rather than treating obese individuals with exogenous leptin, the appropriate approach would be to induce a partial reduction in endogenous circulating leptin by treatment with leptin neutralizing antibody. This avenue might constitute a promising antiobesity and antidiabetic clinical therapy in the near future. ${ }^{15}$ On the other hand, there is only limited research in herbal medicine which makes leptin reduction as a target for obesity therapy. Despite using leptin neutralizing antibody which has a very complicated procedure, herbal medicine is a promising therapy to improve obesity through leptin reduction. This molecular study showed us that Ai as herbal medicine can be developed as an antiobesity that works on leptin reduction mediated by repandusinic acid and mauritanin as $\mathrm{Ai}$ compounds.

\section{Molecular Study of Ai to Alpha glucosidase}

One strategy that has been developed to treat type-2 diabetes, which usually occurs in obesity complication, is inhibition of alpha- glucosidase activity using synthetic drugs. However, these inhibitors are usually associated with gastrointestinal side effects. ${ }^{11}$ Therefore, the development of alpha glucosidase inhibitors from natural products offers an alternative option for the control of hyperglycemia. In recent years, various studies have been conducted to identify alphaglucosidase inhibitors from plants and many candidates have transpired to be secondary metabolites including alkaloids, flavonoids, phenols, and terpenoids. Among these compounds, flavonoid is considered to be responsible for the inhibitory activity of alpha glucosidase because it has a strong antioxidant effect. ${ }^{11}$

Based on the results of the Ai molecular docking study; hesperetin, acaindinin and glucogalin are compounds that have strong bindings to alpha glucosidase on the active site. Among these three compounds, hesperitin has the lowest $\Delta \mathbf{G}(-7.2135 \mathrm{kcal} / \mathrm{ml})$ and the strongest pKI $(11,673)$ than acaindinin and glucogalin. Acaindinin has the moderate $\Delta \mathbf{G}(-6,7586 \mathrm{kcal} / \mathrm{ml})$ and $\mathrm{pKI}(10,331)$ than hesperetin and glucogalin. Hesperetin had 7 hyrogen bonds compared to acaindinin with 5 hydrogen bonds and glucogalin 9 hydrogen bonds. This data showed us that glucogalin has the highest hydrogen bonds to alpha glucosidase, despite the fact that it has the highest $\Delta \mathbf{G}(-5.1502 \mathrm{kcal} / \mathrm{ml})$ and the lowest pKI $(9,823)$ compared to hesperetin and acaindinin. In overall, these three compounds have the most suitable conformation site to inhibiting alpha glucosidase action compare to other compounds of Ai.

From the literature review we found that hesperetin, acaindinin and glucogalin are the member of phenolics or flavonoids compounds. Hesperetin is a natural compound belonging to the flavanone class of flavonoids. It is the aglycone of hesperidin ( $\beta$-7-rutinoside of hesperetin), a predominant flavonoid component of citrus fruits. Although hesperidin exhibits a wide range of biological activities, its aglycone, hesperetin, has a greater bioactivity as a result of more efficient absorption from the intestine, than hesperidin. ${ }^{16}$ Acaindinin is a phenolic compound of $\mathrm{Ai}$, first isolated from $\mathrm{Ai}$ acetone extract in 1997 by Chinese researcher and it has only limited information. ${ }^{17}$ On the other hand, glucogalin is chemical compound formed 
from gallic acid and $\beta$-D-glucose. It is a major component of Emblica officinalis (gooseberry) fruits which have been used for thousands years as a traditional Indian Ayurvedic preparation for the treatment of diabetes in humans. Gooseberry extracts which contain glucogalin have been shown to be efficacious against the progression of cataract in a diabetic rat model. ${ }^{18}$ These data gave a strong suggestion that $\mathrm{Ai}$ may have inhibition activity to alpha glucosidase which is mediated by its polyphenol/flavonoid compounds: hesperetin, acaindinin and glucogalin.

To strengthen the molecular docking results of Ai to alpha glucosidase, we performed an in vitro alpha glucosidase assay to Ai. In vitro alpha glucosidase assay is a parameter that can predict the capability of extract to reduced intestinal glucose assimilation that can attenuate hyperglycaemia. The $\mathrm{IC}_{50}$ value of Ai to alpha glucosidase $(19,429 \mathrm{mg} /$ $\mathrm{ml}$ ) showed that Ai can competitively inhibit the alpha-glucosidase enzyme. This result is in accordance with Saha et al. and Masih et al. which showed that Ai can decrease the sugar blood level in diabetic rats. ${ }^{18,19}$ The result of Saha et al. exhibited a potent hypoglycemic effect of $\mathrm{Ai}$ in streptozotocin-induced diabetic rats given for 28 days. On the other hand, Masih at el. showed the same result of Ai as an antihyperglycaemia in alloxan-induced diabetic Wistar rats. ${ }^{19}$

\section{Phytochemical Compound and a-Glucosidase Inhibitory Activity}

Differences of compounds found among the extracts are caused by the polarity of the solvent and solubility of the samples. ${ }^{20-22}$ Phytochemistry screening of Ai extract in this study showed that Ai contain flavonoid in ethanol and ethyl acetate extract, but not in n-Hexane extract, due to the flavonoid polarity to ethanol and ethyl acetate. Phytochemical test showed that triterpenoid was found in three extracts, flavonoid and tannin found in ethanol and ethyl acetate extracts. Both ethyl acetate and n-hexane contain alkaloid. These phytochemical compounds can be potentially used in diabetes treatment. Flavonoids were reported to inhibiting the alpha-glucosidase activity. ${ }^{23-25}$ Several studies showed that triterpenes isolated from plants inhibit $\alpha$-glucosidase and $\alpha$-amylase. ${ }^{26-28}$ These inhibition activities were also reported from tannin and alkaloid compounds. ${ }^{29,30}$ These compounds found in the extract supported the inhibition activity of the extract. The $\mathrm{IC}_{50}$ of $\mathrm{Ai}$ ethanol extract to alpha glucosidase was $19,429 \mathrm{mg} / \mathrm{ml}$ compared to IC $_{50}$ of Acarbose which was $1,515 \mathrm{mg} / \mathrm{ml}$. The smaller the $\mathrm{IC}_{50}$, the better inhibition activity of the extract towards $a$-Glucosidase. Hence the activity from the Ai extract was not as potent as acarbose. However, the Ai extract was still considered as an antidiabetic agent active category based on its $\mathrm{IC}_{50}$ value compared to the reference. ${ }^{31}$

\section{Ai as Promising Herbal Medicinal to Improve Obesity}

Based on this molecular docking study, we found that Ai can inhibit leptin and alpha glucosidase which play a role in obesity. This makes Ai a suitable herbal candidate to be developed as an antiobesity considering obesity is related to various pathways directed at various types of cells in various stages of the disease process. Further research should do to explore another pathways that Ai could improve in obesity condition.

\section{CONCLUSSION}

The molecular study of Ai to leptin and alpha glucosidase, complemented by in vitro alpha glucosidase assay, suggest that Ai has a strong potency to be developed as antihyperglycaemia-antiobesity. This suggestion requires further research in vitro, in vivo, and in clinical trials.

\section{CONFLICTS OF INTEREST}

The authors declare that there are no conflicts of interest.

\section{ACKNOWLEDGEMENT}

This study was supported by Universitas Indonesia research grant under the scheme "International Indexed Publication Universitas Indonesia 2020" (PUTI UI 2020).

\section{REFERENCES}

1. Zorena K, Jachimowicz-Duda O, Ślęzak D, Robakowska M, Mrugacz M. Adipokines and Obesity. Potential Link to Metabolic Disorders and Chronic Complications. Int J Mol Sci [Internet]. 2020;21(10):3570. Available from: https://www.mdpi.com/1422-0067/21/10/3570

2. World Health Organization. Obesity: Preventing and Managing the Global Epidemic: Report of a WHO Consultationon Obesity. Geneva; 1998.

3. Bray GA, Kim KK, Wilding JPH. Obesity: a chronic relapsing progressive disease process. A position statement of the World Obesity Federation. Obes Rev [Internet]. 2017;18(7):715-23. Available from: http://doi.wiley.com/10.1111/obr.12551

4. ICD. 11-Mortality and Morbidity Statistics.

5. Bozeman SR, Hoaglin DC, Burton TM, Pashos CL, Ben-Joseph $\mathrm{RH}$, Hollenbeak CS. Predicting waist circumference from body mass index. BMC Med Res Methodol [Internet]. 2012;12(1):115. Available from: http://bmcmedresmethodol.biomedcentral.com/ articles/10.1186/1471-2288-12-115.

6. Assefa ST, Yang E-Y, Chae S-Y, Song M, Lee J, Cho M-C, et al. Alpha Glucosidase Inhibitory Activities of Plants with Focus on Common Vegetables. Plants (Basel, Switzerland) [Internet]. 2019;9(1). Available from: http://www.ncbi.nlm.nih.gov/pubmed/31861279

7. Ge T tong, Yao XX, Zhao FL, Zou X han, Yang W, Cui RJ, et al Role of leptin in the regulation of food intake in fasted mice. $J$ Cell Mol Med [Internet]. 2020;24(8):4524-32. Available from: https:// onlinelibrary.wiley.com/doi/abs/10.1111/jcmm.15110

8. Guan X-M, Yu H, Van der Ploeg LH. Evidence of altered hypothalamic pro-opiomelanocortin/ neuropeptide $Y$ mRNA expression in tubby mice. Mol Brain Res [Internet]. 1998;59(2):273-9. Available from: https://linkinghub.elsevier.com/retrieve/pii/S0169328X98001508

9. Koska J, Ortega E, Bogardus C, Krakoff J, Bunt JC. The effect of insulin on net lipid oxidation predicts worsening of insulin resistance and development of type 2 diabetes mellitus. Am J Physiol Metab [Internet]. 2007;293(1):E264-9. Available from: https://www. physiology.org/doi/10.1152/ajpendo.00662.2006

10. Amitani M, Asakawa A, Amitani $H$, Inui $A$. The role of leptin in the control of insulin-glucose axis. Front Neurosci [Internet]. 2013;7. Available from: http://journal.frontiersin.org/article/10.3389/ fnins.2013.00051/abstract

11. Wang L, Tan N, Wang H, Hu J, Diwu W, Wang X. A systematic analysis of natural $\alpha$-glucosidase inhibitors from flavonoids of Radix scutellariae using ultrafiltration UPLC-TripleTOF-MS/MS and network pharmacology. BMC Complement Med Ther [Internet]. 2020;20(1):72. Available from: http://www.ncbi.nlm.nih.gov/ pubmed/32143602

12. Jung $\mathrm{C}-\mathrm{H}$, Kim B-Y, Mok J-O, Kang S-K, Kim C-H. Association between serum adipocytokine levels and microangiopathies in patients with type 2 diabetes mellitus. J Diabetes Investig [Internet]. 2014;5(3):333-9. Available from: http://www.ncbi.nlm. nih.gov/pubmed/24843783

13. Moradi-Afrapoli F, Asghari B, Saeidnia S, Ajani Y, Mirjani M, Malmir $M$, et al. In vitro $\alpha$-glucosidase inhibitory activity of phenolic constituents from aerial parts of Polygonum hyrcanicum. Daru [Internet]. 2012;20(1):37. Available from: http://www.ncbi.nlm.nih. gov/pubmed/23351720

14. Subramaniyan V, Sekar R, Praveenkumar A, Selvam R. Molecular modeling studies of repandusinic acid as potent small molecule for hepatitis B virus through molecular docking and ADME analysis. Quant Biol [Internet]. 2019;7(4):302-12. Available from: https:// journal.hep.com.cn/qb/EN/10.1007/s40484-019-0179-4 
15. Zhao S, Zhu Y, Schultz RD, Li N, He Z, Zhang Z, et al. Partial Leptin Reduction as an Insulin Sensitization and Weight Loss Strategy. Cell Metab [Internet]. 2019;30(4):706-719.e6. Available from: https:// linkinghub.elsevier.com/retrieve/pii/S1550413119304346

16. Bai $X$, Yang $P$, Zhou $Q$, Cai B, Buist-Homan $M$, Cheng $H$, et al. The protective effect of the natural compound hesperetin against fulminant hepatitis in vivo and in vitro. $\mathrm{Br} \mathrm{J}$ Pharmacol [Internet]. 2017;174(1):41-56. Available from: http://www.ncbi.nlm.nih.gov/ pubmed/27714757

17. Ma Y-T, Chuang J-I, Lin J-H, Hsu F-L. Phenolics from Acalypha indica. J Chinese Chem Soc [Internet]. 1997;44(5):499-502. Available from: http://doi.wiley.com/10.1002/jccs.199700075

18. Puppala M, Ponder J, Suryanarayana P, Reddy GB, Petrash JM, LaBarbera D V. The Isolation and Characterization of $\beta$-Glucogallin as a Novel Aldose Reductase Inhibitor from Emblica officinalis. Ramchandran R, editor. PLoS One [Internet]. 2012;7(4):e31399. Available from: https://dx.plos.org/10.1371/journal.pone.0031399

19. Masih M, Banerjee T, Banerjee B, Pal A. ANTIDIABETIC ACTIVITY OF ACALYPHA INDICA LINN. ON NORMAL AND ALLOXAN INDUCED DIABETIC RATS. Int J Phar Phar Sci. 2011;3(3):51-4.

20. Dowlath MJH, Karuppannan SK, GI DR, SB MK, Subramanian S, Arunachalam KD. Effect of Solvents on Phytochemical Composition and Antioxidant Activity of Cardiospermum halicacabum (L.) Extracts. Pharmacogn J [Internet]. 2020;12(6):1241-51. Available from: https://www.phcogj.com/article/1240

21. Lapornik B, Prošek M, Golc Wondra A. Comparison of extracts prepared from plant by-products using different solvents and extraction time. J Food Eng [Internet]. 2005;71(2):214-22. Available from: https://linkinghub.elsevier.com/retrieve/pii/ S0260877404005345

22. Truong D-H, Nguyen DH, Ta NTA, Bui AV, Do TH, Nguyen HC. Evaluation of the Use of Different Solvents for Phytochemical Constituents, Antioxidants, and In Vitro Anti-Inflammatory Activities of Severinia buxifolia. J Food Qual [Internet]. 2019;2019:1-9. Available from: https://www.hindawi.com/journals/jfq/2019/8178294/
23. Al-Ishaq RK, Abotaleb $M$, Kubatka $P$, Kajo K, Büsselberg D. Flavonoids and Their Anti-Diabetic Effects: Cellular Mechanisms and Effects to Improve Blood Sugar Levels. Biomolecules [Internet]. 2019;9(9). Available from: http://www.ncbi.nlm.nih.gov/ pubmed/31480505

24. Escandón-Rivera S, González-Andrade M, Bye R, Linares E, Navarrete A, Mata R. a-glucosidase inhibitors from Brickellia cavanillesii. J Nat Prod [Internet]. 2012;75(5):968-74. Available from: http://www.ncbi.nlm.nih.gov/pubmed/22587572

25. Chen J, Mangelinckx S, Adams A, Wang Z-T, Li W-L, De Kimpe N Natural Flavonoids as Potential Herbal Medication for the Treatment of Diabetes Mellitus and its Complications.

26. Kuang H-X, Li H-W, Wang Q-H, Yang B-Y, Wang Z-B, Xia Y-G. Triterpenoids from the roots of Sanguisorba tenuifolia var. Alba. Molecules [Internet]. 2011;16(6):4642-51. Available from: http:// www.ncbi.nlm.nih.gov/pubmed/21642938

27. Deutschländer $M S$, Lall $N$, Van de Venter $M$, Hussein $A A$. Hypoglycemic evaluation of a new triterpene and other compounds isolated from Euclea undulata Thunb. var. myrtina (Ebenaceae) root bark. J Ethnopharmacol [Internet]. 2011;133(3):1091-5. Available from: http://www.ncbi.nlm.nih.gov/pubmed/21111037

28. Nazaruk J, Borzym-Kluczyk M. The role of triterpenes in the management of diabetes mellitus and its complications. Phytochem Rev [Internet]. 14(4):675-90. Available from: http://www.ncbi.nIm. nih.gov/pubmed/26213526

29. Budi Sasmito B, Puspitasari YE. Antidiabetic and antioxidant activities of tannin extract of Rhizophora mucronata leaves. J Chem Pharm Res. 2016;8(3):143-8.

30. Kumar A, Aswal S, Semwal RB, Chauhan A, Joshi SK, Semwal DK. Role of plant-derived alkaloids against diabetes and diabetesrelated complications: a mechanism-based approach. Phytochem Rev [Internet]. 2019;18(5):1277-98. Available from: http://link. springer.com/10.1007/s11101-019-09648-6

31. Saraswaty V. Alpha Glucosidase Inhibitory activity from Syzygium sp. J Teknol Indones. 2010;33(1):33-7.

\section{GRAPHICAL ABSTRACT}

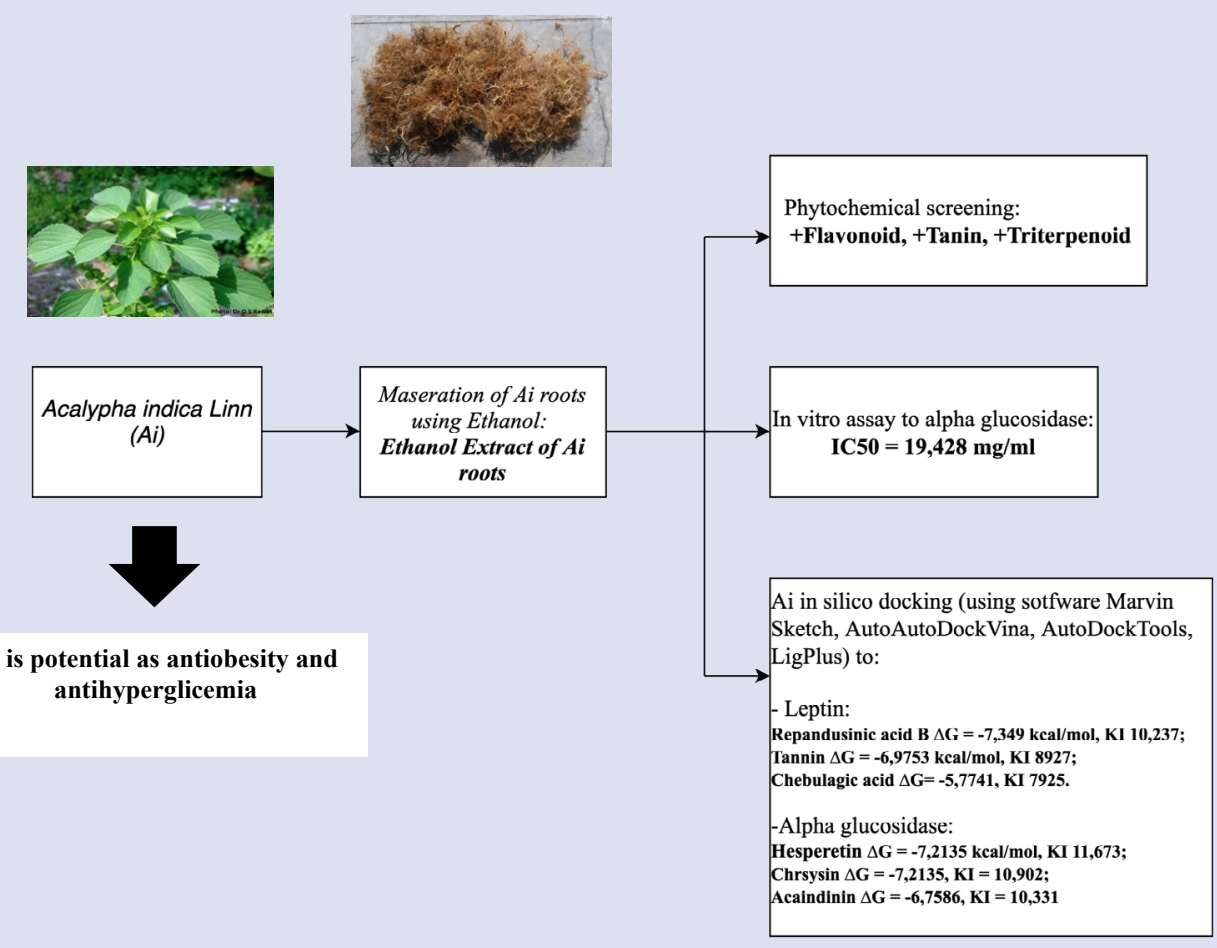




\section{ABOUT AUTHORS}
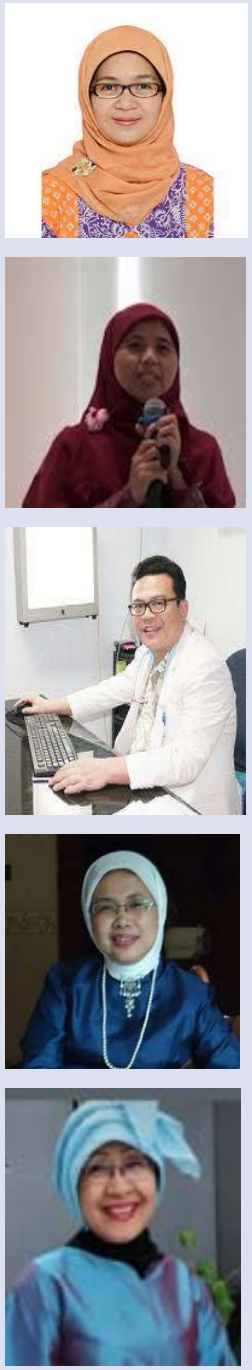

Rani Wardani Hakim is a PhD candidate at Doctoral Program in Biomedical Science-Faculty of Medicine, Universitas Indonesia (FMUI). She is also a staff at Department of Medical Pharmacy-FMUI and member of DDRC-IMERI who has concern about herbal research.

Fadilah Fadilah is a head of Bioinformatics Core Facilities-IMERI Fadilah has an expertise in big data dan bioinformatics research, besides having extensive experience in herbal research and synthetic chemistry. Fadilah is also a staff at Department of Medical Chemistry-FMUI.

Tri Juli Edi Tarigan is an Internal Medicine Specialist who actively serves patients at Cipto Mangunkusumo Hospital, Jakarta, Indonesia. He is also a Head of Endocrine Metabolic Division, Department of Internal Medicine, Cipto Mangukusumo Hospital. In addition to serving patients, he is actively doing research related to endocrine metabolic disease and has interest on herbal medicine for endocrine metabolic disease.

Sri Widia A. Jusman is a professor at Department of Biochemistry-FMUI. Her main research is stress oksidative related to metabolic syndrome disease. She also interested in herbal research that can overcome the oxidative stress parameters caused by metabolic syndrome disease.

Erni H Purwaningsih is a professor at Department of Medical Pharmacy-FMUI. She is a Head of Indonesian Herbal Medicine Science and Indonesian Complementary Traditional Health Professional Association who has a great interest in herbal research and has many publications related to Indonesian herbal.

Cite this article: Hakim RW, Fadilah F, Tarigan THE, Jusman SWA, Purwaningsih EH. Molecular Study of Acalypha indica to Leptin, Alpha Glucosidase, and its Antihyperglycemic Effect on Alpha Glucosidase. Pharmacogn J. 2021;13(6)Suppl: 1639-1647. 